\title{
Cracking behaviour and its effect on the deflection of patched-reinforced concrete beam under flexural loading
}

\author{
Stefanus Kristiawan ${ }^{1, *}$, Agus Supriyadi ${ }^{1}$, Senot Sangadji ${ }^{1}$ and Duwi Santosa ${ }^{2}$ \\ ${ }^{1}$ SMARTCrete Research Group, Civil Engineering Department, Universitas Sebelas Maret, Surakarta \\ 57126, Indonesia \\ ${ }^{2}$ Civil Engineering Department, Universitas Sebelas Maret, Surakarta 57126, Indonesia
}

\begin{abstract}
Under the influence of aggressive environment, structural concrete could exhibit degradation in various forms. One of the symptoms of the degradation could be shown in the form of local delamination of concrete cover. Patching method could be a preference choice to repair this type of degradation to regain its structural performance and durability. This paper presents the structural behaviour of patched-reinforced concrete beam under flexural loading with particular interest on the use of unsaturated polyester resin (UPR) mortar as patch repair material. The repair area is replicated in the tensile zone of the beam. The behaviour investigated in this study is the cracking evolution of the patched reinforced concrete beam and its effect on the deflection. It is shown that the higher strength of the UPR-mortar leads to a reduction in the intensity of cracks compared to that of un-repaired (normal) reinforced concrete beam. The lesser cracks intensity is beneficial to restore the flexural stiffness of the beam.
\end{abstract}

\section{Introduction}

Reinforced concrete (RC) beam is a part of building structural system elements, which is designed to sustain flexural and shear loading. The design approach as specified in various Codes [1, 2] suggests that the RC beam should be designed to fail in a ductile manner. Since the rupture of RC beam due to shear stress is a brittle one [3], consequently the shear capacity of the beam must be intended to be more conservative than the corresponding flexural strength. It means any excessive loads beyond the design load should lead to flexural type of failure. However, a proper design would take into account any kinds of imposed loads throughout its service life and therefore, failure of the beam element should not be expected. A part from the strength, the design of RC beam must also satisfy the serviceability requirements. An example of serviceability requirement is a maximum limit of deflection $[4,5]$. The magnitude of deflection is determined by the flexural stiffness of the beam which in turn is influenced by the elastic modulus of concrete and reinforcement,

\footnotetext{
* Corresponding author: s.a.kristiawan@ft.uns.ac.id
} 
the dimension of the beam, the amount of the reinforcement, creep and shrinkage of concrete. The last two properties contribute to the long-term deflection $[6,7]$.

The instantaneous deflection of RC beam as a response of loading could be traced from its load-deflection behaviour. Figure 1 illustrates the complete behaviour of RC beam under flexural loading up to failure. The load-deflection curve of RC beam may be divided into three regions [8]: the first region (I) is defined from a zero load to a load causing an initiation of first flexural crack (cracking load). This region could also be viewed as a precracking region where the un-cracked beam behaves fully linear elastic; the second region (II) is counted from the cracking load to a load causing the first yield of the reinforcement (yield load). This region corresponds to post-cracking region where RC beam is cracks at various intensity depending on the load level. The higher the load, the more the intensity of the cracks. The present of cracks certainly affects the rigidity (flexural stiffness $E I$ ) of the beam. At this region the moment of inertia of the beam lies between the moment of inertia of gross section $\left(I_{g}\right)$ and the moment of inertia of fully cracked section $\left(I_{c r}\right)$; finally the third region (III) is counted from the yield load to a failure load where the beam behaves as nonlinear elastic material.

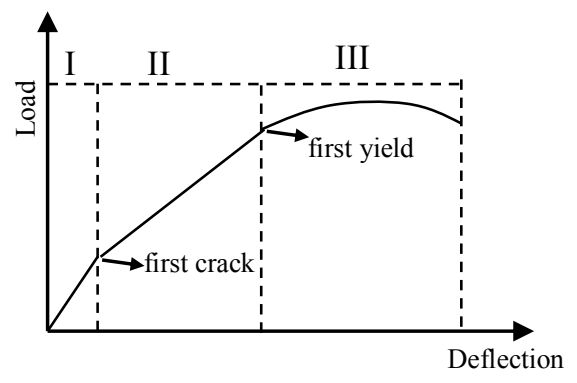

Fig. 1. Load-deflection of RC beam

Generally the service load falls within region II. Hence, the deflection at this load level is of interest. The deflection of the RC beam at service load has to consider the rigidity of the beam at this region. The rigidity of $\mathrm{RC}$ beam is a transitional value between rigidity of un-cracked beam and fully cracked beam [9]. This transitional value is represented by the value of effective moment of inertia of the section $\left(I_{e}\right)$ which lies between $I_{g}$ and $I_{c r}$. The value of $I_{e}$ depends upon the extent of cracking caused by applied loads. The following formula is suggested to estimate the $I_{e}[1]$ :

$$
I_{e}=\left(\frac{M_{c r}}{M_{a}}\right)^{3} I_{g}+\left[1-\left(\frac{M_{c r}}{M_{a}}\right)^{3}\right] I_{c r}
$$

where $M_{c r}$ and $M_{a}$ representing the cracking moment and the maximum moment due to the service load, respectively. $M_{c r}$ could be calculated from:

$$
M_{c r}=\frac{f_{r} I_{g}}{y_{b}}
$$

where $f_{r}$ and $y_{b}$ is the modulus of rupture of concrete and the distance of the bottom fiber to the neutral axis of the RC beam, respectively. The value of $f_{r}$ may be predicted from the compressive strength of the concrete $f^{\prime} c$ using the following relation: 


$$
f_{r}=0.7 \sqrt{f_{c}^{\prime}}
$$

The moment of inertia of both normal and patched RC beam at un-cracked or cracked section with various amount of reinforcements may be calculated by considering the transformed-area.

The total deflection of RC beam at service load should be maintained within the maximum limit throughout its service life. However, there are circumstances that could alter the magnitude of deflection of the RC beam such as degradation of the beam element. The degradation of RC beam is commonly observed in structures exposed to aggressive enivronments. The degradation could be visually detected in the form of spalling or local delamination of concrete cover. The flexural stiffness of RC beam at this damaged zone will be lower compared to the rest of the beam which in turn altering the magnitude of beam deflection. Any repairs carry out to recover the damaged zone should be expected to resume both the strength and serviceability of the RC beam [10].

Patch repair is a common method to recover the spalling of concrete cover. The method requires a suitable repair material that should satisfy various specifications. They include the requirement of adhesive/bond to the parent concrete, strength, elastic modulus, shrinkage, creep, coefficient of thermal expansion, durability, etc [11]. The requirements are specified to ensure the compatibility of the repair material with the parent concrete in term of dimensional, mechanical and durability. An unsaturated polyester resin (UPR) mortar has been developed by the authors to meet those specifications [12-14]. The performance of RC beams pacthed with this material has been studied with respect to the influence of various patching parameters [15-16]. For the current research, UPR mortar will be investigated with special interest to observe the cracking intensity and its effect on the deflection of patched-RC beam under flexural loading. For this purpose, a comparison of the load-deflection behaviour of patched-RC beam to that of normal $\mathrm{RC}$ beam is determined experimentally. Since the load-deflection behaviour of RC beams at region II is influenced by the cracking intensity of the beams, the evolution of cracking of both beams at various load levels within this region are inspected carefully. The influence of the cracking intensity will be further examined to compare the deflection of both beams.

\section{Experimental Investigation}

For the purpose of this investigation, two type of beams were prepared i.e. normal RC beam and patched-RC beams. Both beams had similar size and reinforcements (see Figure 2). The repair area was replicated at the tensile zone of the RC beam along the maximum moment. The thickness of the repair was specified at $70 \mathrm{~mm}$. The beams were prepared with a concrete where the proportion of which was determined on the basis of average strength of $25 \mathrm{MPa}$. The beams were cast into wooden moulds and the moulds were striped off on the following day after casting. The beams were then cured with wet burlaps for 28 days and subsequently they were stored in the laboratory environment for about 3 months. A day before testing, one of the RC beams was patched with unsaturated polyester resin (UPR) mortar. The UPR mortar was prepared using the following ingredients and proportion as per $1 \mathrm{~m}^{3}: 808 \mathrm{~kg}$ of cement, $143 \mathrm{~kg}$ of fly ash, $950 \mathrm{~kg}$ of sand, $475 \mathrm{~kg}$ of UPR and $24 \mathrm{~kg}$ of hardener. The hardener was required to initiate the polymerization of UPR. No water was added in the UPR mortar mix. Hence, both cement and fly ash could be considered as filler materials.

The actual properties of concrete, UPR mortar and steel reinforcement are shown in Table 1 . The $28 \mathrm{~d}$ compressive strength and elastic modulus of concrete were determined on cylinder $(150 \times 300 \mathrm{~mm})$ specimens following ASTM C39 and ASTM C469, 
respectively. The compressive strength of UPR mortar was tested at $1 \mathrm{~d}$ of age on cubes of $5 \times 5 \times 5 \mathrm{~mm}$ in accordance with ASTM C109. Meanwhile, the elastic modulus of UPR mortar was determined on cylinder $(75 \times 150 \mathrm{~mm})$ specimens using similar procedure as that of testing elastic modulus of concrete. The flexural strength of UPR mortar was determined in according to ASTC C580. Finally, the steel reinforcement was tested in tension up to failure using Universal Testing Machine (UTM). All the values given in Table 2 were calculated as an average of at least three results.

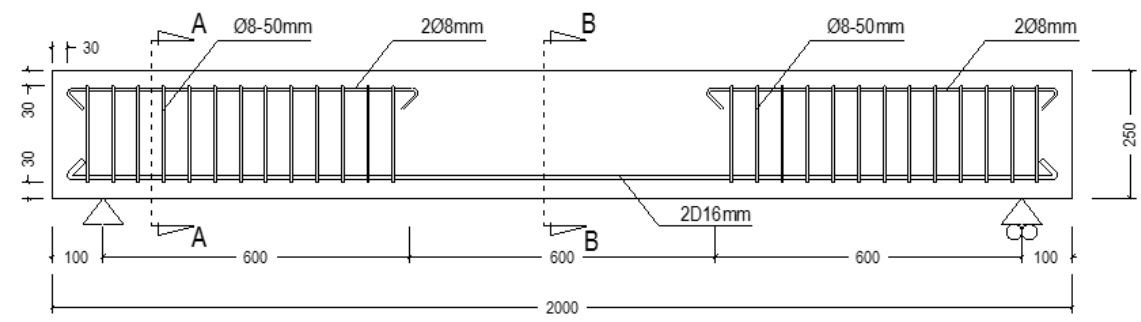

a. Normal RC beam
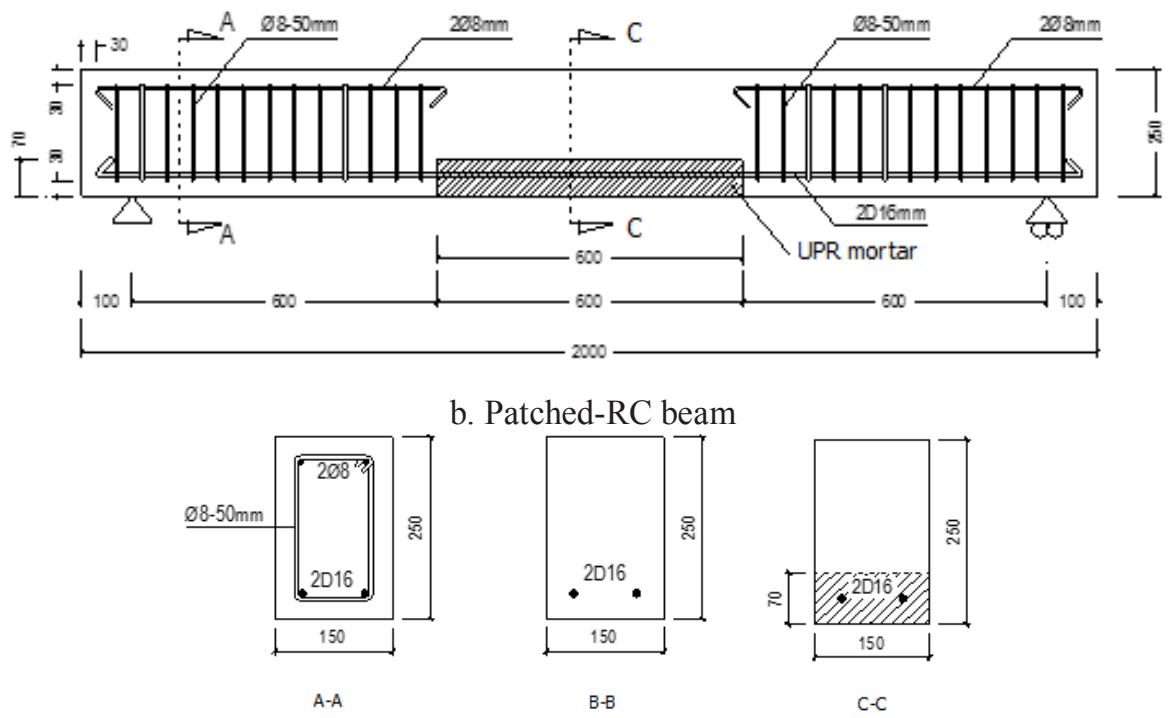

c. Cross-section

Fig. 2. RC beam specimens with detail of reinforcements

Table 1. Properties of materials

\begin{tabular}{|l|c|c|c|}
\hline \multicolumn{1}{|c|}{ Property } & Concrete (MPa) & UPR mortar (MPa) & Steel (MPa) \\
\hline Compressive strength & 30.23 & 76.33 & NA \\
\hline Flexural strength & $3.85^{*}$ & 23 & NA \\
\hline Yield strength & NA & NA & 437 \\
\hline Elastic modulus & 24225 & 13557 & $200000^{* *}$ \\
\hline
\end{tabular}

"predicted value based on Eq. (3); ${ }^{* *}$ assumed value 


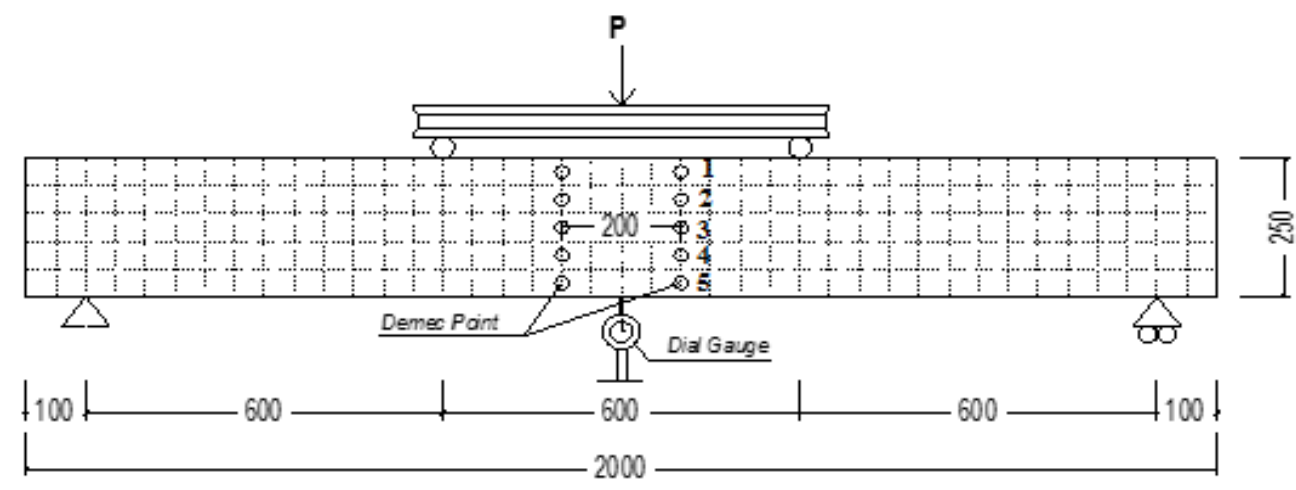

Fig. 3. Schematic loading of RC beam flexural testing

The flexural testing of RC beams were schematically shown in Figure 3. The load P was applied and incrementally increased at $200 \mathrm{~kg}$ until the beams were rupture. At each increment of load, the corresponding deflection at the mid-span was measured using dial gauge. The deformations of the beams at both compression and tension zone were checked by measuring the distance between pair of demec points at location shown in Figure 3 using Demec gauge. Visual examination was carried to monitor the evolution of cracks on the beams at each increment of loading.

\section{Results and discussion}

\subsection{Cracking evolution}

The evolution of crackings on the normal RC beam and patched-RC beam under increment of flexural loading are illustrated in Figure 4. The first flexural cracks on the normal RC beam appear at a load of $2 \mathrm{~T}$. These cracks occur at a zone where the moment is maximum. In contrast to the normal RC beam, the first flexural cracks of the patched-RC beam (induced by load of $2.8 \mathrm{~T}$ ) appear beyond the maximum moment zone. The present of UPR mortar at this zone could be accountable for this behaviour. At a load of $2.8 \mathrm{~T}$, the calculated maximum tensile stress is only 5.9 MPa. The value of this stress is computed with the moment of inertia of gross section $I_{g}$ after taking into account the transformed areas. Clearly, the level of this tensile stress is far below the modulus of rupture of UPR mortar $(23 \mathrm{MPa})$. In fact the experimental result shows that the first cracks of UPR mortar occur at a load of $10 \mathrm{~T}$. This level of load induces a maximum tensile stress of $21.24 \mathrm{MPa}$ which is close to the modulus of rupture of UPR mortar. It is also interesting to note that the flexural cracks appearing in the UPR mortar do not propagate to the parent concrete. The cracks is discontinued within the thickness of UPR mortar. In fact the first crack of parent concrete at location above the repair zone occurs at $9 \mathrm{~T}$ of loading while no cracks are observed in the UPR mortar at this level of loading.

Figure 4 shows the distinctive cracks development between the normal $\mathrm{RC}$ beam and patched-RC beam as the applied load is increased. For the normal RC beam, the cracks are initially within the maximum moment zone when low level of loading is applied; after which the cracks also emerge at both the shear span zones. At high level of loading it seems that the cracks are distributed almost evenly along the span length of the beam. On the other hand, the cracks on the patched-RC beam are initially clustered beyond the repair zone. The cracks only appear at the repair zone (maximum moment) after high loading is applied (at least 10T). It is also clearly shown that the cracking intensity of the normal RC beam is 
greater than that of the patched-RC beam. Comparing these two cracking intensities, it can be conviniently concluded that the patched-RC beam is better in maintaining the rigidity of the beam at the post-cracking region.

The final cracks patterns at rupture are interesting to be examined. For the normal RC beam, the final flexural cracks reach depths in such that the compression zone of concrete is left to about $50 \mathrm{~mm}$. The mode of failure is initiated by yielding of the reinforcements (shown in Figure 6.a). Any attempts to impose an increase of load at this state will cause a significant deformation of the reinforcements and at some point trigger compression fracture of concrete located just under point loads. For patched-RC beam, the mode of failure is also initiated by yielding of the reinfocements. However, the final cracks display different pattern to that of normal RC beam. The flexural crack of concrete above the repair zone propagates and diverges into two directions toward point loads. These directions of cracks suggest that the propagation of cracks are influenced by the compressive stresses trajectory. The final cracks pattern in the compression zone indicates that an increase of load beyond the post yield limit will ultimately causes concrete to fail predominantly due to high compressive stress at this zone.
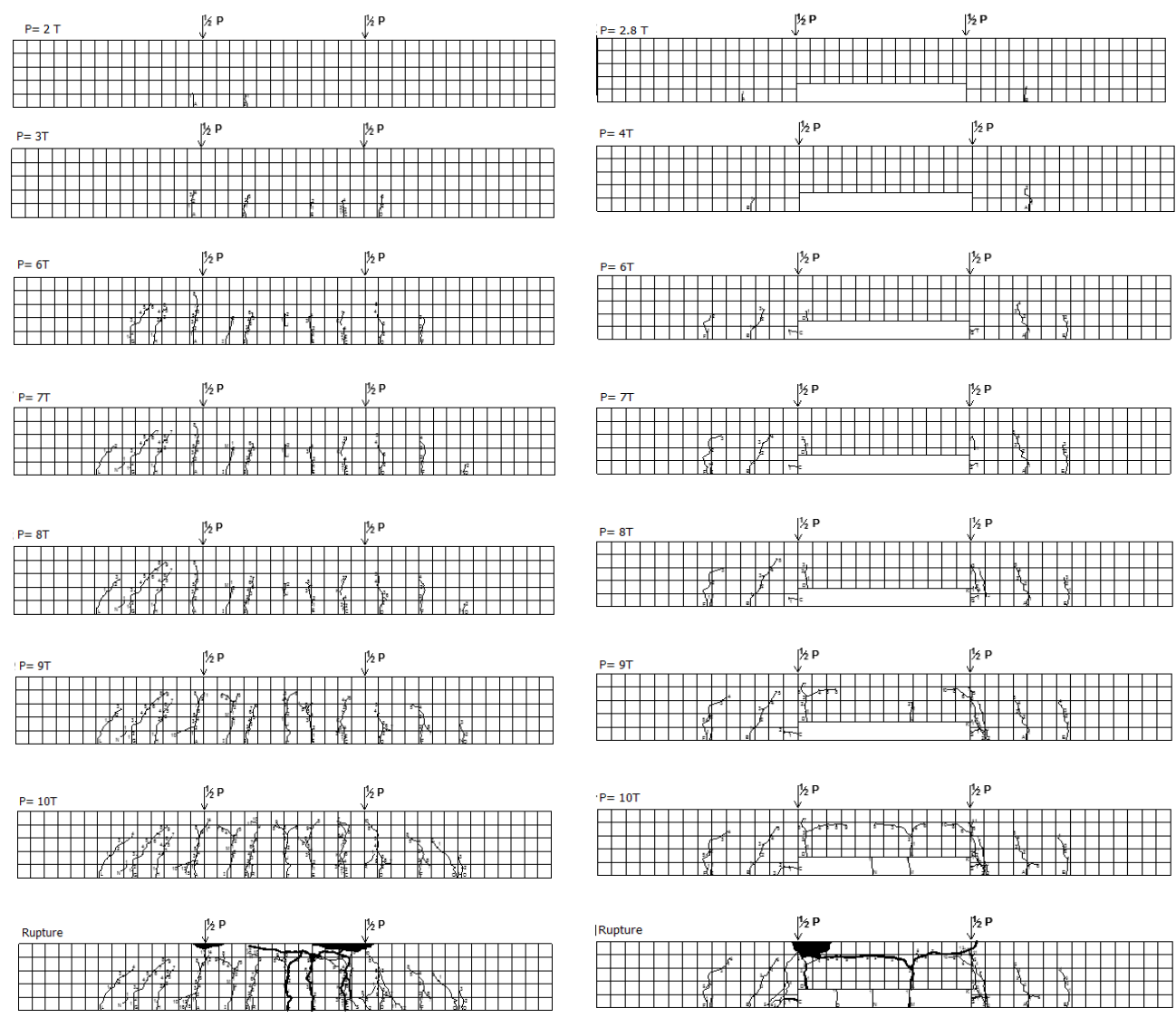

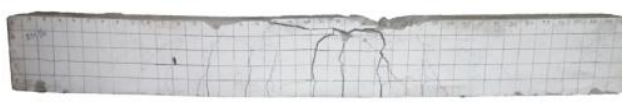

a. Normal RC beam

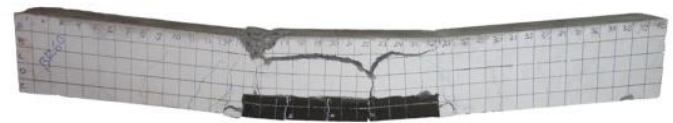

b. Patched-RC beam

Fig. 4. Evolution of cracking on RC beam under increment of flexural loading 


\subsection{Deformation of beam at compression and tension zone}

$\mathrm{RC}$ beam will undergo compressive and tensile deformations at above and below neutral axis, respectively when it is loaded in flexure. The highest deformations will be observed in the middle span of the beam. For this reason the deformations at this location is investigated in this research. The deformations both at compression and tension zone are measured by monitoring the change in the distance between pairs of demec points shown in Figure 3. The measured deformations of the RC beams under increment of flexural loading are given in Figure 5.
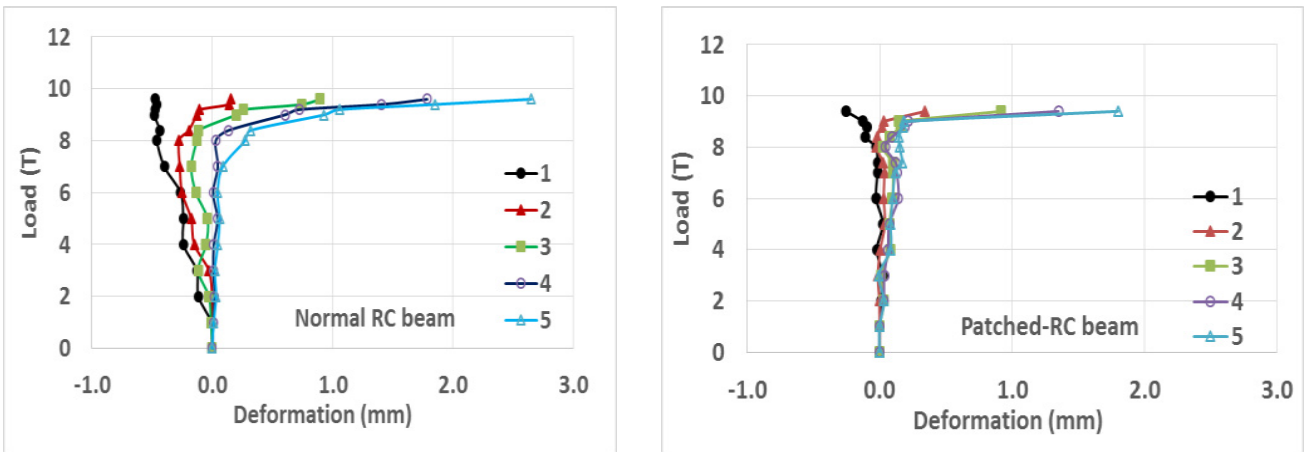

Fig. 5. The deformations of normal (left) and patched (right) RC beam at compression and tension zone

Initially the first three layers designated by number 1,2 and 3 of normal $\mathrm{RC}$ beam show compression deformation (negative value) as given in Figure 5.a. These deformations indicate that these layers are within the area of compression zone. The neutral axis of the normal $\mathrm{RC}$ beam is lower than a half of the beam height (at layer number 3 ). The tensile reinforcements in this cross-section is accountable for lowering the neutral axis from its original position of plain concrete beam. The propagation of cracks certainly influence the deformations of the beam. At about $8 \mathrm{~T}$ of loading, the compressive deformations of layer number 2 and 3 start to change in their directions toward positive values. At this level of loading, the depth of cracks already penetrate the compression zone (see Figure 4.a). Hence, the neutral axis moves upward causing the layer number 2 and 3 turn to be in the tensile zone. Only layer number 1 is still in the compression zone. The $8 \mathrm{~T}$ of loading also corresponds to yielding of the tensile reinforcements as indicated by large deformations of the tensile zone (see also Figure 6.a).

For patched-RC beam, it appears that only layer number 1 and 2 undergo compressive stresses. The presence of UPR mortar with low elastic modulus (about a half of that concrete as shown in Table 1) is accountable for this characteristic. Considering transformed area, the $I_{g}$ of this repaired section is lower than that of normal RC beam. The neutral axis of the patched-RC beam is at a higher position compared to that of normal RC beam. Hence, the compression zone of the beam is smaller. At $8 \mathrm{~T}$ of loading, similar behaviour to that of normal RC beam is observed. At this level of loading, it is marked as the beginning of large deformations in the tensile zone. It is also a starting point where the neutral axis shifts upward causing layer number 2 turns to be in the tensile zone. Comparing to those of normal $\mathrm{RC}$ beam, it is obvious that the magnitudes of deformations observed in the patched-RC beam are lower. The behaviour could be related to the cracking pattern of the beams. At $8 \mathrm{~T}$ of loading, the patched-RC beam shows no cracks at all at the middle span. On the other hand, a number of crack propagations are observed in normal RC beam (see Figure 4). Cracking is a sign that a sufficient magnitude of tensile stresses 
exhibits in the zone leading to significant deformations which eventually initiate cracks and their propagations. A very high tensile strength of UPR mortar is beneficial to delay the initiation of cracks. Consequently, the deformations at the observed zone of patched-RC beam are retained at low level before cracking.

\subsection{Load-deflection behaviour}

The deflection of both RC beams under increment of flexural loading is presented in Figure 6. The complete curve determined from the zero loading to the rupture is given in Figure 6.a while the short curve representing load-deflection behaviour from the zero loading to the yield loading is shown in Figure 6.b. The figures suggest that both RC beams generally have a similar behaviour. Initially the deflection is proportional to the applied load. After the normal $\mathrm{RC}$ beam exhibits cracks at about $2 \mathrm{~T}$ of loading, the flexural stiffness of this beam is only slightly reduced. The deflection is a little bit higher at an equal increment of loading than the deflection at the pre-cracking region. The deflection at post-cracking region can still be considered linear with a little lower flexural stiffness compared to that of pre-cracking region. For patched-RC beam the proportional limit of load-deflection is maintained at a higher level of loading compared to that of normal RC beam i.e. at about 5 $\mathrm{T}$ before the curve deviates a little downward. It seems that the presence of one little crack at each of the shear span of patched-RC beam do not affect the flexural stiffness of the patched-RC beam. Only cracks appeared at high load level will affect the flexural stiffness of patched-RC beam.

Theoretically, the initial flexural stiffness of the patched-RC beam is lower than the flexural stiffness of normal RC beam. The $I_{g}$ of patched-RC beam calculated by taking into account the transformed areas equals to $168939220.7 \mathrm{~mm}^{4}$. This value is smaller than the $I_{g}$ of normal RC beam which is $209083612.6 \mathrm{~mm}^{4}$. However, the difference in Ig only occurs on middle span segment where patch repair exists. It may be expected that this difference of $I_{g}$ would cause the initial deflection of the patched-RC beam is a little higher. The experimental results hardly confirm this. The normal RC beam develops cracks at early loading than the patched-RC beam. Hence, the flexural stiffness of the normal RC beam begins to reduce at early loading. The flexural stiffness of the beam at post-cracking region is calculated on the basis of $I_{e}$ given in Eq. (1). However, this equation is not appropriate for patched-RC beam which shows difference cracking pattern and intensity. The complexity of the problem is also induced by the alteration of neutral axis position where patched-RC beam deforms differently to the normal RC beam. The cracking pattern and intensity of patched-RC beam make the beam is sufficient to maintain its rigidity up to a very high loading. Consequently, the deflection of this beam at post-cracking region is surpassed by the deflection of the normal RC beam.

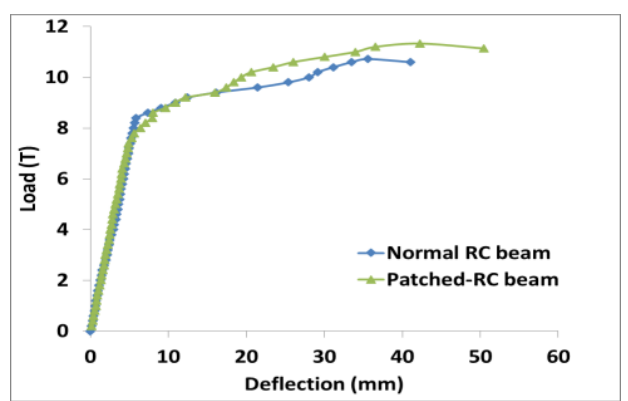

a. Complete curve

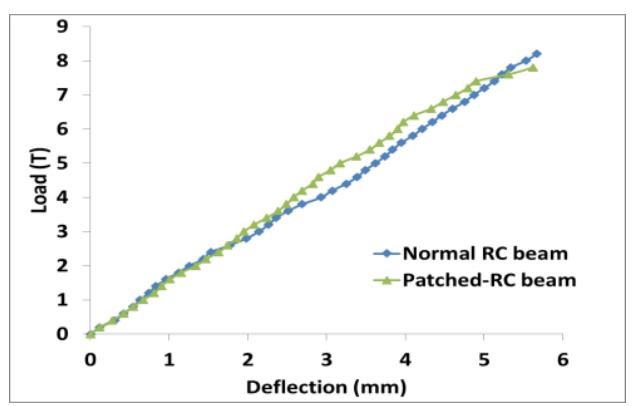

b. Up to yield load

Fig.6. Load-deflection behaviour 


\section{Conclusions}

UPR mortar has been used to patch a replicated damage in the tensile zone of RC beam. The performance of the patched-RC beam is compared to the normal $\mathrm{RC}$ beam. The following conclusions are drawn:

- the presence of UPR mortar could delay the first appearance of flexural cracks

- the evolution of cracks in the patched-RC beam begins and cluster beyond the repaired zone while for the normal $\mathrm{RC}$ beam it begins in the maximum moment zone and then distributed evenly along the span length of the beam

- the cracking intensity of patched-RC beam is less than that of normal RC beam

- the presence of UPR mortar could also reduce the magnitude of deformations in the middle span of the beam

- the flexural rigidity of the patched-RC beam is maintained at higher level of loading than that of normal RC beam

- the deflection of the patched-RC beam at post-cracking region is slightly less than that of normal $\mathrm{RC}$ beam as a consequence of retaining its rigidity

This research is a part of the research project under the Hibah Kompetensi Scheme which financially supported by DRPM Dirjen Risbang, Kemenristek Dikti, Indonesia.

\section{References}

1. ACI Committee 318, Building Code Requirements for Structural Concrete (ACI 318M08) and Commentary (American Concrete Institute, Farmington Hill, 2008)

2. International Federation for Structural Concrete (fib), Model Code for Concrete Structures 2010 (Wilhelm Ernst \& Sohn, Berlin, 2013)

3. J.Y. Lee, S.W. Kim and M.Y. Mansour, J. Struct. Eng. 137, 1017-1029 (2011)

4. M.A. Rashid and M.A. Mansur, ACI Struct. J. 102, 462-471 (2005)

5. A.S. Desalegne and A.S. Lubell, ACI Struct. J. 109, 867-877 (2012)

6. W.C. Choi and H.D. Yu, Mat. Des. 51, 742-750 (2013)

7. A. Abrishambaf, J.A.O. Barros and V.M.C.F. Cunha, Cem. Con. Res. 72, 21-36 (2015)

8. E.G. Nawy, Prestressed Concrete: A Fundamental Approach (Prentice Hall, Upper Saddle River, 2010)

9. J.C. McCormac and R.H. Brown, Design of Reinforced Concrete (Wiley, New Jersey, 2014)

10. R. Sahamitmongkol, S. Suwathanangkul, P. Phoothong and Y Kato, Adv. Con. Tech. 6, 317-336 (2008)

11. International Concrete Repair Institute, Guide for Selecting and Specifying Materials for Repair of Concrete Surfaces (ICRI, 1996)

12. S.A. Kristiawan and A.B. Prakoso, App. Mech. Mat. 754-755, 442-446 (2015)

13. S.A. Kristiawan and A.B. Prakoso, Mat. Sci. For. 857, 426-430 (2016)

14. S.A. Kristiawan and R.S. Fitrianto, IOP Con. Ser. Mat. Sci. Eng. 176, 012017 (2017)

15. A. Supriyadi, S.A. Kristiawan and S.B. Raditya, App. Mech. Mat. 754-755, 457-462 (2015)

16. S.A. Kristiawan, A. Supriyadi and M.K. Muktamirin, Effect of patching thickness on the flexural performance of patched reinforced concrete beams, Advances in Civil, Architectural, Structural and Constructional Engineering, Taylor \& Francis (2016) 
17. S.A. Kristiawan, A. Supriyadi, S. Sangadji and H.B. Wicaksono, K. Eng. Mat. 737, 441-447 (2017) 